\title{
Determination of Heavy Metals in Cosmetics Used in Bangalore Metropolitan City
}

\author{
K. L. Prakash" ${ }^{*}$ and Manjushree, M. S
}

Department of Environmental Science, Bangalore University, Gnana Bharathi, Bengaluru, Karnataka 560056, India

\begin{tabular}{ll}
\hline DOI: $\underline{10.36348 / S J L S .2019 . v 04 i 09.003}$ & | Received: 02.10.2019| Accepted: 09.10.2019| Published: 25.10 .2019 \\
*Corresponding author: Dr. K. L Prakash &
\end{tabular}

Abstract

The paper highlights the metallic contents of cosmetic product includes whitening cream and lipstick of different brand and colour and they are commonly used products in Bangalore city. Sample were analysed to determine the heavy metals like Copper $(\mathrm{Cu})$, Iron $(\mathrm{Fe})$ and Nickel (Ni) using Atomic absorption spectrophotometer (F-AAS). The heavy metals like $\mathrm{Cu}, \mathrm{Fe}$ and $\mathrm{Ni}$ were detected in all the samples with varying concentration except iron, iron was below detectable level in lipstick samples. The concentrations (ppm) of Iron (Fe) ranged between BDL and 4.4881ppm in both lipstick samples and whitening creams samples. The concentration of Copper $(\mathrm{Cu})$ ranged from $0.5392 \mathrm{ppm}$ to $0.5054 \mathrm{ppm}$ in lipstick samples and $0.5704 \mathrm{ppm}$ to $0.495 \mathrm{ppm}$ in whitening creams. The concentration of Nickel (Ni) ranged from $28.2911 \mathrm{ppm}$ to $26.713 \mathrm{ppm}$ in lipstick samples and $31.383 \mathrm{ppm}$ to $27.670 \mathrm{ppm}$ in whitening cream. The partial elimination of heavy metals from cosmetic products after manufacturing can be possible. However, the quality of the products can be improved by consideration of raw materials and heavy metal levels. The excessive use of cosmetics should be discouraged by public awareness. Therefore, efforts are necessary to make aware of the users and the general public especially pregnant women and children about the harmful consequences of cosmetics use. It is suggested to regular monitoring of heavy metals and chemicals used in cosmetics as pose health risk among the users.

Keywords: Cosmetics, Toxicity, trace metals, health effects.

Copyright @ 2019: This is an open-access article distributed under the terms of the Creative Commons Attribution license which permits unrestricted use, distribution, and reproduction in any medium for non-commercial use (NonCommercial, or CC-BY-NC) provided the original author and source are credited.

\section{INTRODUCTION}

Cosmetic products or its related any substance are proposed to be placed in connection with several outer parts of the body i.e. skin, nails, lips and external organs or applied to the teeth and mucous membranes of the oral cavity which mostly used for beautification, scrubbing, protection, changing their entrance and keeping for fitted body. Main ingredient of cosmetics are some surfactants, oils and other ingredients which are required to be active, long durable, sustainable and safe for human use. Since the modern civilization, most of the cosmetics industries produce synthetic products because of easy manufacturing process and possibly to avoiding the dependency on the natural raw sources [1, $2]$.

Cosmetics are made available for the cleansing, beautifying or altering appearance and enhancing attractive features of the human body [3-5]. But cosmetics are not the same thing as medicines and cosmetics cannot be used to alter a body's functions or performance [6]. Even today makeup plays an important role for both men and women in many of the regions. Cosmetics are prepared with various ingredients both organic and hypoallergenic form to meet the demands of users. Accordingly, the most common cosmetics are readily available today in the form of creams, lipstick, perfumes, eye shadows, nail polishes, hair sprays etc in addition to face powder used to glow up the skin after applying the base cream.

The Indian cosmetic Industry is significantly grown up compared recent past decades. Because of these cosmetic and beauty products were being used very widely since from long period in India. The similar observation noticed Asian countries like India, China, Japan, and Korea. Such products occupy $61 \%$ of dermatological market in India [7].

The color cosmetics viz., nail varnish, lipsticks and lip glosses account for the most sales, particularly, local brands like Lakme and Revlon and a significant decreased growth have noticed among anti-wrinkle creams, cleaners and toners, facial creams, moisturizers and fairness creams. Skin allergies and dermatitis may be increased by contact due to the presence of heavy 
metals in cosmetics $[8,9]$. Some of the companies like Ponds and Fair and Lovely rule the roost in this segment.

Explosion of the demand of cosmetics in market is mainly by beauty consciousness of people, consequently the side effects as well as health consciousness of people has attracted the clinicians and researchers to find out the route cause of the side effects. Heavy metal contamination is one of the important reasons behind the same problem, viz, lead and cadmium are common contaminant in various cosmetic products [10-15]. Sin K.W et al., and McKelvey, W et al., studies showed that the presences of excess chromium concentration in cosmetics [16, 17].

Many studies have been significantly enlisted an association between some ingredients of cosmetics and various health problems. The common side-effects of skin lightening cosmetics include both cutaneous and extra cutaneous effects [18], whereas skin bleaching can harm foetal development in pregnant skin bleachers [19]. Comparatively, females are at greater health risk in developing countries due to inadequate nutrition, unhealthy lifestyle, and more fashion about cosmetics. The subsequent consequences not only physiological changes but also can alter the bioaccumulation pattern of these metals in the body. Most of the metals act as endocrine disrupters interfering with female hormonal system [20].

The continuous and frequent use of these cosmetic products could lead to the absorption of metals through skin. Particularly, facial cosmetics are used daily and applied to the thinnest area of the facial skin, such as the peri-occular areas, and lips, where absorption may be very high. Lipstick products are unconsciously ingested and therefore present an obvious oral route of exposure to metal contaminants in cosmetics, although lipstick product is intended to topical use.

Metals are of environmental and human health significance because they exhibit a wide range of toxic and chronic health effects, such as cancer; reproductive, developmental and neurological disorders; cardiovascular, kidney and as well as renal problems; in addition to lung damage; contact dermatitis; brittle hair and hair loss. Many are implicated as endocrine disruptors and respiratory toxins. The use of cosmetics has been known to cause sensitization, dermatitis, allergic reactions and to be an important route of exposure to metals in humans [21].

Cosmetics products need to be regularly monitored for trace metals contents and should be constantly regulated to understand and minimize their impact on health and safety issues of human beings [22, 23]. Hazard-based research evidences have clearly demonstrated the health impact of long term exposure to trace metals like cancer, reproductive, immune and nervous system toxicity [24-27]. As there are not much research data available on the presence of trace metals in cosmetics and their toxicity issues with respect to India in general and Karnataka in particular, the present study is one such initiative on a pilot scale to reveal the levels of some major trace heavy metals in some of the selected cosmetic products with objective to study trace metal concentration in selected cosmetics (viz., Lipsticks and whitening creams).

\section{MATERIAL AND METHODS}

Sampling and digestion of cosmetic products

A total of 4 samples of lipsticks and 6 samples of fairness creams were purchased from local shops of Bangalore. The details of cosmetics products used are presented in Table-1.

Table-1: Details of Cosmetic samples selected in the present study

\begin{tabular}{|c|c|c|c|c|c|}
\hline Sl. No & Sample code & Brand & colour & Manufactured By & Use before \\
\hline \multicolumn{6}{|c|}{ LIPSTICK } \\
\hline 1 & LS1 & Lakme & & Hindustan unilever Ltd & $03 / 2019$ \\
\hline 2 & LS2 & Colorbar & & Viva cosmetics & $12 / 2020$ \\
\hline 3 & LS3 & Maybelline & & Usa & $10 / 2019$ \\
\hline 4 & LS4 & Lotus & $\begin{array}{c}\text { Orange } \\
\text { spice }\end{array}$ & Regi India cosmetics Pvt Ltd & $10 / 2018$ \\
\hline \multicolumn{6}{|c|}{ WHITENING CREAM } \\
\hline 1 & WC1 & Ponds white beauty & $\begin{array}{l}\text { Pinkish } \\
\text { white }\end{array}$ & Hindustan unilever Ltd. & $09 / 2018$ \\
\hline 2 & WC2 & Garnier white complete & $\begin{array}{l}\text { Creamy } \\
\text { white }\end{array}$ & Loreal india pvt.Ltd & $06 / 2019$ \\
\hline 3 & WC3 & Olay natural white & Pink & & \\
\hline 4 & WC4 & $\begin{array}{c}\text { Fair \& lovely advanced } \\
\text { multivitamin }\end{array}$ & White & Hindustan unilever Ltd & $06 / 2019$ \\
\hline 5 & WC5 & Meglow fairness & & Indo herbal product & $4 / 2018$ \\
\hline 6 & WC6 & Lotus white glow & White & Lotus herbal color cosmetics & $06 / 2020$ \\
\hline
\end{tabular}


The acid wet digestion method was followed for the elemental determination, previously described in the article by [12]. The samples were digested and analyzed for the 8 heavy metals $(\mathrm{Ni}, \mathrm{Cd}, \mathrm{Fe}, \mathrm{Co}, \mathrm{Pb}, \mathrm{Zn}$, $\mathrm{Mn}$, and $\mathrm{Cu}$ ) using an Atomic absorption spectrometer (Shimadzu make, model: AA-6300 with Flame furnace).

\section{RESULTS AND CONCLUSION}

Majority of the cases, unregulated chemical content of skin lightening products, especially in developing countries is alarming, whereas, the European Union Cosmetics Directive highlights the lead and their compounds as unacceptable constituents of cosmetic products [28]. The cosmetic product includes whitening cream and lipstick of different brand and colour and they are commonly used products in Bangalore city. Sample were analysed to determine the heavy metals like Copper $(\mathrm{Cu})$, Iron $(\mathrm{Fe})$ and Nickel (Ni) using Atomic absorption spectrophotometer (FAAS). The heavy metals like $\mathrm{Cu}, \mathrm{Fe}$ and $\mathrm{Ni}$ were detected in all the samples with varying concentration except iron, iron was below detectable level in lipstick samples. It is very important understand the maximum permissible concentration of heavy metals among the different age groups where as children are more susceptible to heavy metal poisoning compared to adults, quantum of product used and the site of applied $[29,30]$. The level of both copper $(\mathrm{Cu})$ and Nickel (Ni) were the highest in the comparison to the other metals. The concentration of Iron (Fe) ranged between BDL and 4.4881ppm in both lipstick samples and whitening creams samples the concentrations were below detectable level. The concentration of Copper $(\mathrm{Cu})$ ranged from $0.5392 \mathrm{ppm}$ to $0.5054 \mathrm{ppm}$ in lipstick samples and $0.5704 \mathrm{ppm}$ to $0.495 \mathrm{ppm}$ in whitening creams. The concentration of Nickel $(\mathrm{Ni})$ ranged from $28.2911 \mathrm{ppm}$ to $26.713 \mathrm{ppm}$ in lipstick samples and $31.383 \mathrm{ppm}$ to $27.670 \mathrm{ppm}$ in whitening cream (Fig $1 \&$ 2). However, iron was not detected in most of the samples. Ni showed a highest concentration where as a minimum concentration was noticed by copper. The excessive use of cosmetic products which are contaminated with toxic heavy metals may lead to slow release of the metals into the human body and accumulate in the body tissues and hence cause certain health complications. In India cosmetic products are regulated under the drugs and cosmetics act 1940 and rules 1945 and labelling declarations are regulated by Bureau of Indian Standards (BIS) [31]. It is difficult to eliminate completely heavy metals from cosmetic products as metals are a part of the cosmetics, whereas, the quality of the products can be improved by consideration of raw materials and heavy metal levels. Therefore, it is necessary to have more studies need to be taken up for determining the concentration of heavy metals in other brands of cosmetics which are marketed in elsewhere. It is significant to understand that maximum permissible concentration of heavy metals vary according to sub-population interest as children are more susceptible to heavy metal poisoning compared adults, the amount of product used and the site of application $[29,30]$. The excessive use of cosmetics should be discouraged by public awareness. This study is help to aware people about heavy metal contamination in cosmetic products. Therefore, efforts must be made to inform the users and the general public especially pregnant women and children about the harmful consequences of cosmetic use.

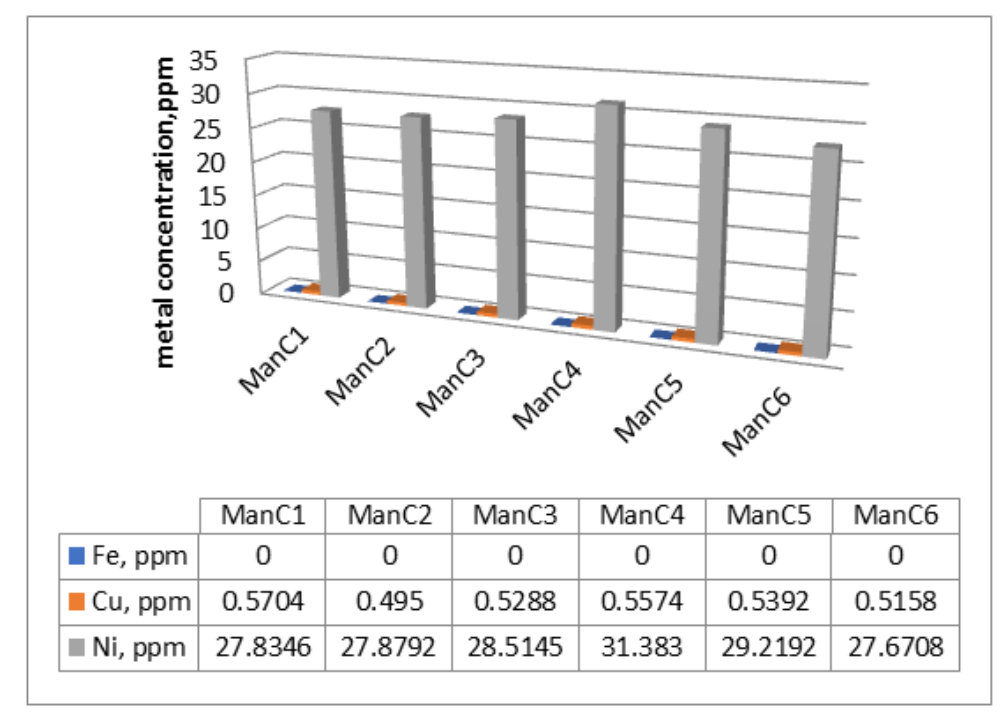

Fig-1: Heavy metal concentration (ppm) in different brands of whitening cream 


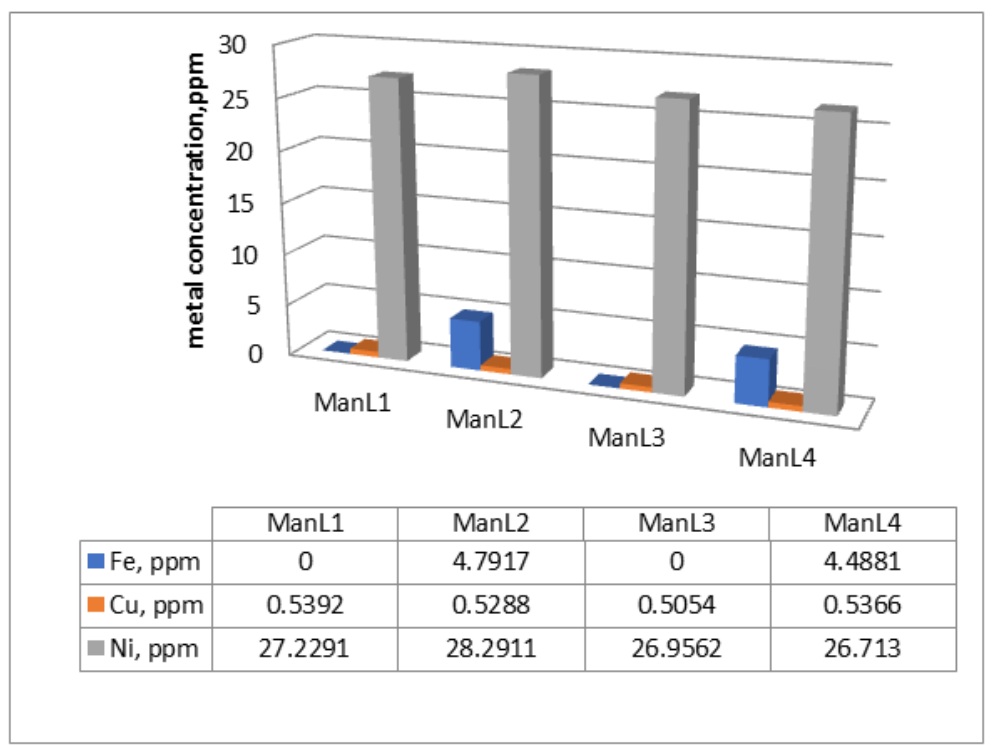

Fig-2: Heavy metal concentration (ppm) in different brand of lipstick samples

Based on the observations, it is recommended to monitor heavy metals and chemicals regularly during the manufacture of cosmetics products which may cause health risks to users. Specialised laboratories should be provided for determining these trace metal concentration in cosmetic products and need to be done to ascertain their safety. Manufacturer should follow the good manufacturing practice before the cosmetic is packaged in finished form. If the heavy metal is still exists in the finished cosmetic products at an insignificant level and does not have any technical or functional effect then it must be ensured by the manufacturer that the finished cosmetic product contains the lowest levels possible of heavy metals. So it does not exceed the limits set by health authorities. People who use cosmetics should know that these products may have toxic ingredient such as heavy metals.

\section{ACKNOWLEDGMENT}

Authors acknowledge the support of Department of Environmental Science, Bangalore University Bangalore for providing laboratory facilities.

\section{REFERENCES}

1. Nadeem, S. (2014). Fair and anxious: On mimicry and skin lightening in India. Social Identities, 20(2-3), 224-238.

2. Islam, F., Morshed, A. J. M., Rahman, M., Akhtar, P., Islam, M. J., Mahmud, A. S. M., ... \& Heng, L. Y. (2015). Determination of Heavy Metals and Trace Elements in Worldwide Branded Shampoo Available in Local Market of Bangladesh by Atomic Absorption Spectrometry. Asian Journal of Chemistry, 27(10), 3756-3762.

3. Saeed, M., Muhammad, N., \& Khan, H. (2011). Assessment of heavy metal content of branded Pakistani herbal products. Tropical Journal of Pharmaceutical Research, 10(4), 499-506.
4. Theresa, O. C., Onebunne, O. C., Dorcas, W. A., \& Ajani, O. I. (2011). Potentially toxic metals exposure from body creams sold in Lagos, Nigeria. Researcher, 3(1), 30-37.

5. Muhammad, D. F., \& Stephen, P. B. (2014). Study of heavy metals content in facial cosmetics obtained from open markets and superstores within Kaduna Metropolis. Nigeria Am J Chem Appl, 1, 27-33.

6. Borowska, S., \& Brzóska, M. M. (2015). Metals in cosmetics: Implications for human health. Journal of Applied Toxicology, 35(6), 551-572.

7. Anitha, J., \& Ray, J. G. (2018). Toxic content of certain commercially available fairness creams in Indian market. Cogent Medicine, 5, 1-8.

8. Ayenimo, J. G., Yusuf, A. M., \& Adekunle, A. S. (2009). Heavy Metal Exposure from personal care products. Bull Environ Contam Toxicol, 84(1), 814.

9. Health Canada. (2011). Toxic metals found in make-up cosmetics. A report released by Environmental Defiance, 23-26.

10. Nnorom, I. C., Igwe, J. C., \& Oji-Nnorom, C. G. (2005). Trace metal contents of facial (make-up) cosmetics commonly used in Nigeria. African Journal of Biotechnology, 4(10), 1133-1138.

11. Chauhan, A. S., Bhadauria, R., Singh, A. K., Lodhi, S. S., Chaturvedi, D. K., \& Tomar, V. S. (2010). Determination of lead and cadmium in cosmetic products. Journal of Chemical and Pharmaceutical Research, 2(6), 92-97.

12. Nasirudeen, M. B., \& Amaechi, A. U. (2015). Spectrophotometric determination of heavy metals in cosmetics sourced from Kaduna Metropolis, Nigeria. Science World Journal, 10(3), 1-5.

13. Iwegbue, C. M., Bassey, F. I., Tesi, G. O., Onyeloni, S. O., Obi, G., \& Martincigh, B. S. (2015). Safety evaluation of metal exposure from commonly used moisturizing and skin-lightening 
creams in Nigeria. Regulatory Toxicology and Pharmacology, 71(3), 484-490.

14. Siti Zulaikha, R., Sharifah Norkhadijah, S. I., \& Praveena, S. M. (2015). Hazardous ingredients in cosmetics and personal care products and health concern: a review. Public Health Res, 5(1), 7-15.

15. Noor abdul Hakeem Abdul Razzaq Al-Baheley. (2017). Study the concentration of heavy metals in some Cosmetics and their health effects on humans. Journal of Environmental Science, Toxicology and Food Technology, 11(8), 50-54.

16. Sin, K. W., \& Tsang, H. F. (2003). Large scale mercury exposure due to a cream cosmetic: community wide case series. Hong Kong Medical Journal, 9, 329-334.

17. McKelvey, W., Jeffery, N., Clark, N., Kass, D., \& Parsons, P. J. (2010). Population- Based inorganic Mercury Biomonitoring and the Identification of Skin Care Products as a Source of Exposure in New York City. Environ Health Perspect, 119, 203-209.

18. De Groot, A. C., Nater, J. P., \& Weyland, J. W. (1994). Unwanted effects of cosmetics and drugs used in dermatology. Elsevier, 1-3.

19. Street, J. C., Gaska, K., Lewis, K. M., \& Wilson, M. L. (2014). Skin bleaching. A neglected form of injury and threat to global skin. African Safety Promotion Journal, 12(1), 52-71.

20. Orisakwe, O. E., \& Otaraku, J. O. (2013). Metal concentrations in cosmetics commonly used in Nigeria. The Scientific World Journal, 2013, 1-7.

21. Eltaweel, Y., Nassef, E. M., Hazza, R. (2014). Recovery of copper from wastewater by cementation technique. World Environ, 4(5), 199205.

22. Omolaoye, J., Uzairu, A., \& Gimba, C. (2010). Heavy metal assessment of some eye shadow products imported into Nigeria from
China. Archives of Applied Science

Research, 2(5), 76-84.

23. Samia, S. B., Rehab, M. E., Hatem, A. M., AlOtaiqe, R., Banan, A. A. (2017). Detection of heavy metals in cosmetic creams and antiperspirants marketed in saudiarabia. World Journal of Pharmaceutical and Medical Research, 3(1), 30-39.

24. Borba, C. E., Guirardello, R., Silva, E. A., Veit, M. T., \& Tavares, C. R. G. (2006). Removal of nickel (II) ions from aqueous solution by biosorption in a fixed bed column: experimental and theoretical breakthrough curves. Biochemical Engineering Journal, 30(2), 184-191.

25. Oyaro, N., Ogendi, J., Murago, E. N., \& Gitonga, E. (2007). The contents of $\mathrm{Pb}, \mathrm{Cu}, \mathrm{Zn}$ and $\mathrm{Cd}$ in meat in nairobi, Kenya. International Journal Food Agricultural Environ, 5, 119-121.

26. Fu, F., \& Wang, Q. (2011). Removal of heavy metal ions from wastewaters: a review. Journal of environmental management, 92(3), 407-418.

27. Sani, A., Gaya, M. B., \& Abubakar, F. A. (2016). Determination of some heavy metals in selected cosmetic products sold in kano metropolis, Nigeria. Toxicology reports, 3, 866-869.

28. Salvador, A., \& Chisvert, A. (2007). Analysis of cosmetic products. Amsterdam. Elsevier, 487.

29. Adepoju-Bello, A. A., Oguntibeju, O. O., Adebisi, R. A., Okpala, N., \& Coker, H. A. (2012). Evaluation of the concentration of toxic metal in cosmetic products in Nigeria. Journal of Biotechnology, 11(97), 16360 - 16364.

30. Health Canada. (2012). Guidance on Heavy metals impurities in cosmetics. Retrieved April, 2015.Available from http: // www.hc-sc.gc.ca.

31. Sahu, R., Saxena, P., \& Johnson, S. (2014). Heavy metals in Cosmetics. Centre for Science and Environment, 1-28. 